$\mathbf{R}_{\text {ESEARCH }} \mathbf{P}_{\text {APER }} \longrightarrow \begin{aligned} & \text { FOOD SCIENCE } \\ & \text { RESEARCH JOURNAL }\end{aligned}$

\title{
Dietary pattern of post-menopausal women
}

\author{
D. PraveEna
}

\begin{abstract}
Menopause is perhaps the most striking event occurring during the middle age in women and represents the end of woman's reproductive life. Women spend a significant part of their lives in post-menopausal states. The present study was conducted on 600 postmenopausal women in Thiruvanathapuram district to assess their dietary pattern. Pretested interview schedule was administered in person to the women by the investigator. Dietary adequacy was assessed by 24 $\mathrm{hr}$ recall method and the mean individual intake of nutrients was compared with the Recommended Dietary Allowance (RDA).Results showed pulses green leafy vegetables, eggs, meat, preserved foods were least frequently used foods. Data revealed that the diet of the women were inadequate in major and micronutrients.
\end{abstract}

Key Words : Post-menopausal women, Dietary pattern, Recommended dietary pattern

How to cite this article : Praveena, D. (2015). Dietary pattern of post-menopausal women. Food Sci. Res. J., 6(2): 268-272. 